\title{
Caracterização energética das madeiras de clones de Eucalyptus cultivados em diferentes localidades
}

\author{
Angélica de Cássia Oliveira Carneiro' ${ }^{1}$, Benedito Rocha Vital ${ }^{1}$, Pedro Gustavo Ulisses Frederico', \\ Clarissa Gusmão Figueiró ${ }^{1}$, Lucas de Freitas Fialho ${ }^{1 \star}$, Carlos Miguel Simões da Silva ${ }^{1}$ \\ ${ }^{1}$ Departamento de Engenharia Florestal, Universidade Federal de Viçosa (UFV), Viçosa, Brasil.
}

\begin{abstract}
RESUMO O objetivo deste trabalho foi avaliar o efeito do material genético e do local de plantio na qualidade da madeira de eucalipto, proveniente de sistemas de curta rotação, para fins energéticos, assim como analisar a correlação existente entre as propriedades da madeira. Avaliou-se cinco clones de Eucalyptus spp. provenientes de três munícipios do estado de Minas Gerais, sendo mensurados os seguintes parâmetros da madeira: Os teores de extrativos, ligninas e holoceluloses, densidade básica e poder calorífico superior. As propriedades estudadas apresentaram valores de acordo aos indicados para a produção de carvão vegetal e geração de energia. Quando se objetiva a queima direta, para a produção de energia, os clones IV e V apresentaram o maior potencial de utilização, para todas as regiões estudadas. Em contrapartida, quando se objetiva a produção de carvão vegetal os clones V e II apresentaram o maior potencial de utilização, sendo o primeiro mais indicado para as regiões de Santa Bárbara e Guanhães e do segundo para a região de Ipaba.
\end{abstract}

Palavras-chave: Local de plantio; queima direta; poder calorífico superior; carvão vegetal.

\section{Energetic characterization of the wood from Eucalyptus clones grown in different localities}

\begin{abstract}
The objective of this study was to evaluate the energy quality of the wood from Eucalyptus clones harvested with reduced age in different localities of the state of Minas Gerais. Five clones of Eucalyptus spp. planted in three municipalities in the state of Minas Gerais were evaluated. The following wood parameters were measured: extractive, lignin and holocellulose contents, basic density and higher heating value. The properties studied presented values according of charcoal production and for energy generation. When direct burning was aimed at energy production, clones IV and V showed the greatest potential for use in all the studied regions. On the other hand, for the production of charcoal, clones V and II presented the greatest potential of use, of which the first one was more indicated for the regions of Santa Bárbara and Guanhães, and the second one for the region of Ipaba.
\end{abstract}

Keywords: Planting site; direct burning; higher heating value; charcoal.

\section{Introdução}

A madeira é um material caracteristicamente heterogêneo que apresenta alta variabilidade nas suas propriedades gerais, sejam elas anatômicas, químicas, físicas ou térmicas. A heterogeneidade é inerente à própria genética, idade da madeira e às condições de crescimento em que o espécime arbóreo foi submetido (OLIVEIRA et al., 2012; CASTRO et al., 2013). A variabilidade pode ocorrer entre gêneros, espécies, variedades, clones, indivíduos, no sentido base-topo e no sentido medula-casca (EVANGELISTA et al., 2010).

A maioria das propriedades da madeira e de seus derivados apresentam algum tipo de correlação. A variabilidade natural, portanto, influencia diretamente no rendimento e na qualidade dos produtos oriundos das indústrias de base florestal. Assim, caracterizar essa variabilidade e correlaciona-la 
com a utilização final torna-se uma etapa essencial para a correta destinação da matéria-prima (OLIVEIRA et al., 2012; PEREIRA et al., 2012).

Quando se avalia a produção de energia, pode-se dizer que a utilização da madeira se segmenta na produção de carvão vegetal (carbonização) e a queima direta (combustão) (VALE et al., 2002). Entretanto, para cada tipo de utilização, a matéria-prima deve apresentar propriedades adequadas de acordo com o produto final. Desta forma, o uso da madeira como fonte energética depende da identificação das propriedades de maior interesse, das interações entre elas, e da quantificação da sua importância (VITAL et al., 2013). Para a produção de carvão vegetal, por exemplo, preferem-se materiais com maiores densidades e maiores teores de lignina (CASTRO et al., 2013).

Atualmente, a demanda crescente por madeira induz o setor de florestas plantadas a investir em pesquisa para, cada vez mais, aumentar a produtividade dos plantios e reduzir a idade de corte. Nesse contexto, as florestas de curta rotação surgem como alternativas, para obtenção deste produto em intervalos de tempo reduzido e com custos inferiores de produção (ELOY et al., 2014). De acordo com García et al. (2013) e Cruzado et al. (2011), os sistemas de curta rotação podem apresentar-se potencias para atender o mercado energético, uma vez que, é possível obter grandes volumes de biomassa lignocelulósica em curtos períodos de tempo quando comparado aos plantios convencionais.

Todavia, quando oriunda de plantios de curta rotação, esta matéria-prima apresenta qualidade distinta das produzidas em sistemas florestais convencionais devido à variabilidade que ocorre em função da idade do indivíduo (OLIVEIRA et al., 2010). Assim, o estabelecimento de florestas para a produção de energia envolve a seleção de materiais genéticos superiores, aliando a produtividade das florestas com a qualidade desejada da madeira para fins energéticos.
Com isso, o objetivo deste estudo foi avaliar a qualidade energética das madeiras de clones de Eucalyptus colhidos com idade reduzida em diferentes localidades do estado de Minas Gerais.

\section{Material e Métodos}

Foram avaliadas amostras de madeiras de cinco materiais genéticos, com idade de três anos, sendo o clone I proveniente da espécie Eucalyptus grandis e os clones II, III, IV e V de híbridos das espécies Eucalyptus grandis $\mathrm{x}$ Eucalyptus urophylla. As árvores foram coletadas em um plantio experimental com espaçamento de 3,0 x 3,3 m.

Os dados foram analisados segundo um fatorial $5 \times 3$ (cinco materiais genéticos e três localidades de plantio), com cinco repetições (árvores), totalizando 75 unidades amostrais. Os materiais genéticos foram cultivados em três localidades do estado de Minas Gerais:

- Santa Bárbara (Mesorregião Metropolitana de Belo Horizonte): Maior índice de pluviosidade anual (1400-1600 $\mathrm{mm}$ ); solo de profundidade variada, textura argilo-arenosa e baixa fertilidade natural;

- Guanhães (Mesorregião do Vale do Rio Doce): Menor índice de pluviosidade anual (1100-1200 mm); solo profundo, textura argilosa e de baixa fertilidade natura;

- Ipaba (Mesorregião do Vale do Rio Doce): Menor índice de pluviosidade anual (1000-1200 mm); solo profundo, textura argilo-arenosa e de alta fertilidade natural.

As árvores selecionadas como amostra para cada material, apresentavam com diâmetro médio em uma parcela de $10 \mathrm{x}$ 10 plantas. De cada árvore foram retirados toretes a $0 \%, 25 \%$, $50 \%, 75 \%$ e $100 \%$ da altura comercial considerada até o diâmetro mínimo de sete centímetros.

A densidade básica da madeira foi determinada de acordo com o método de imersão em água, seguindo as normas descritas pela NBR 11941 (ABNT, 2003). 
Tabela 1. Valores de altura e DAP dos clones utilizados.

Table 1. Values of height and DAP of the clones.

\begin{tabular}{cccccc}
\hline & I & II & III & IV & V \\
\hline Santa Bárbara & & & & & \\
\hline DAP (cm) & 40,40 & 43,20 & 42,10 & 41,60 & 41,20 \\
Alt. Total (m) & 19,30 & 21,68 & 20,92 & 18,58 & 20,08 \\
Alt. Comercial (m) & 13,05 & 16,14 & 13,93 & 12,10 & 13,77 \\
\hline Guanhães & & & & & \\
\hline DAP (cm) & 29,49 & 42,90 & 40,50 & 42,00 & 44,50 \\
Alt. Total (m) & 15,94 & 22,26 & 19,86 & 19,06 & 22,24 \\
Alt. Comercial (m) & 10,40 & 15,30 & 13,23 & 12,55 & 15,24 \\
\hline Ipaba & & & & & \\
\hline DAP (cm) & 12,25 & 12,25 & 12,60 & 13,70 & 13,50 \\
Alt. Total (m) & 20,18 & 20,52 & 20,76 & 19,50 & 20,56 \\
Alt. Comercial (m) & 13,59 & 13,59 & 13,42 & 12,78 & 13,33
\end{tabular}

$\mathrm{DAP}=$ Diâmetro à altura do peito médio; Alt. Total = Média das alturas totais das arvores selecionadas; Alt. Comercial = Média das alturas comerciais das arvores selecionadas.

A composição química estrutural foi obtida para a determinação dos teores de lignina, holoceluloses e extrativos. As amostras foram moídas e selecionadas as amostras que passaram pela peneira de malha 40 mesh e ficaram retida na peneira de malha 60 mesh (ASTM, 1982).

Os teores de extrativos da madeira foram determinados em duplicatas, de acordo com a norma TAPPI 204 om-88 (TAPPI, 1996), utilizando-se o método de determinação de extrativos totais, apenas substituindo o etanol/benzeno pelo etanol/tolueno.

Os teores de lignina insolúvel foram determinados em duplicata pelo método Klason, modificado de acordo com o procedimento proposto por Gomide e Demuner (1986). A lignina solúvel foi determinada por espectrometria, conforme Goldschimid (1971), a partir da diluição do filtrado proveniente do procedimento para obtenção da lignina insolúvel. O teor de lignina total foi obtido por meio da soma dos valores de lignina solúvel e insolúvel.

O Poder Calorífico Superior foi determinado de acordo com a metodologia descrita pela norma DIN EN 14918 (2010), utilizando-se uma bomba calorimétrica adiabática.
Os dados foram analisados segundo um delineamento fatorial tipo $5 \times 3$ (cinco materiais genéticos e três localidades de plantio), com cinco repetições (árvores) cada. Os resultados foram submetidos à análise de variância (ANOVA) e, quando estabelecidas diferenças significativas, os tratamentos foram comparados entre si por meio do teste de Tukey a $5 \%$ de significância. Para determinar as correlações entre as propriedades, foi empregado o coeficiente de correlação de Pearson, que mede o grau de associação linear entre duas variáveis quantitativas. A significância das correlações foi determinada por meio do teste de Tukey a 5\% de significância.

\section{Resultados e Discussão}

Na Figura 1 são apresentados os valores médios da densidade básica dos clones em função do local de plantio. Observa-se que, de modo geral, houve efeito significativo das duas variáveis nos valores de densidade encontrados.

A maior densidade básica da madeira foi apresentada pelo clone III, nas três localidades avaliadas. $\mathrm{Na}$ região de Santa Bárbara e Ipaba, observa-se que o material genético III apresentou maior densidade básica da madeira. Para a região de Guanhães, os materiais genéticos de maior densidade foram os III, IV e V. Os valores de densidade básica da madeira são semelhantes aos encontrados nas literaturas Carneiro et al. (2014) e Trugilho et al. (2015) estudando diferentes clones de eucalipto aos 3 anos de idade.

As condições ambientais têm influência nas atividades cambiais de formação da madeira e na sua anatomia (OLIVEIRA et al., 2012). Como a densidade da madeira é resultado da combinação da quantidade e distribuição dos diferentes elementos anatômicos, pode-se dizer que as variações edafoclimáticas, portanto, podem afetar a densidade de forma positiva ou negativa. 


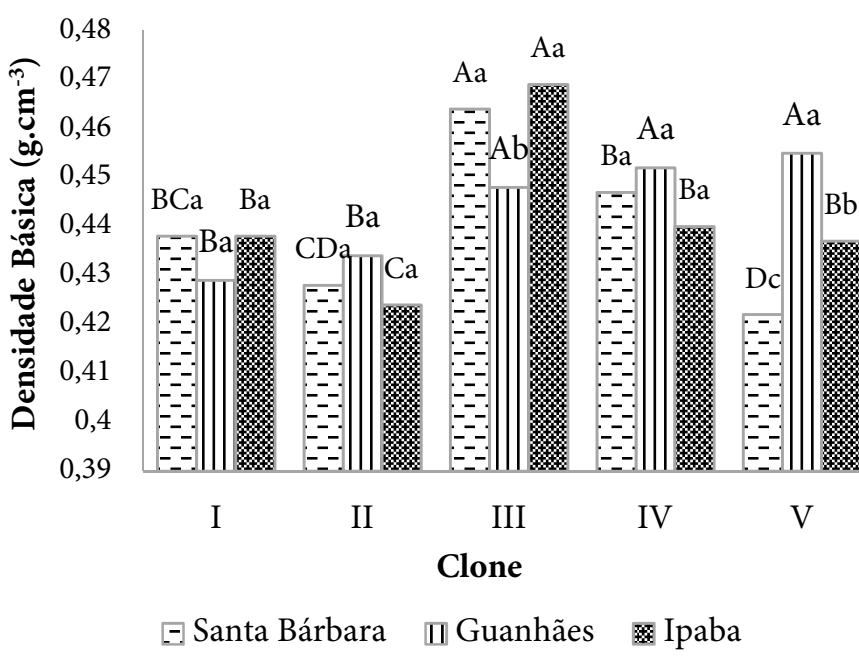

Médias seguidas de letras maiúsculas comparam clones e letras minúsculas compara as regiões de plantios pelo teste Tukey a 5\% de significância.

Figura 1. Densidade básica da madeira de Eucalyptus sp. em função do material genético e do local de plantio.

Figure 1. Basic density of Eucalyptus sp. wood as a function of genetic material and planting site.

Madeiras mais jovens tendem a ter densidade menores em decorrência da maior proporção de lenho juvenil presente na composição do seu tronco (VIDAURRE et al., 2011). A utilização de madeiras colhidas com idades reduzidas de corte deve, portanto, ser analisadas, uma vez que a baixa densidade é indesejável para a produção de energia e carvão vegetal. Conforme discutido por Hill et al. (2013), baixas densidades podem diminuir a eficiência e o rendimento nas etapas de transporte, conversão e utilização da madeira.

A densidade básica da madeira está diretamente relacionada com a produção de energia, ou seja, quanto maior a densidade, maior a quantidade de energia estocada por unidade de volume (PEREIRA et al., 2012). Dessa maneira, a densidade é um dos principais parâmetros utilizados para subsidiar a escolha de materiais genéticos para fins energéticos. Além disso, a carbonização de madeiras mais densas é preferível por aumentar a produtividade das unidades produtoras de carvão e, normalmente, resultar em produtos de maior qualidade físico-mecânica, ou seja, mais densos e resistentes (OLIVEIRA et al., 2010).

Na Figura 2 são apresentados os valores médios do teor de extrativos totais dos clones em função do local de plantio. Observa-se que, de modo geral, houve efeito significativo das duas variáveis nos valores desta propriedade.

Os menores teores de extrativos na madeira dos clones foram observados na região de Santa Bárbara, enquanto que os maiores teores foram observados para a região de Ipaba, exceto para os clones III e IV. Na região de Ipaba os solos apresentam a menor precipitação e o maior déficit hídrico, o que pode ter ocasionado o aumento no teor de extrativos na madeira dos clones, como uma resposta a condições adversas do ambiente.

Segundo Silva; Trugilho (2003) o processo que cernificção é caracterizado não só pela morte das células do parênquima radial, mas também pelo consumo de amido e pelo aumento no conteúdo de extrativos e tilos. Portanto, madeiras colhidas com idade reduzidas, como foi o caso deste trabalho, tendem a apresentar um teor de extrativos inferior as madeiras colhidas em idades de cortes convencionais, uma vez que apresenta o processo de cernificação pouco intensificado.

Os extrativos da madeira perfazem um grupo heterogêneo e diversificado de compostos orgânicos, incluindo lipídios, compostos fenólicos, terpenóides, ácidos graxos, ésteres, ceras e muitos outros compostos (ROWELL et al., 2005). O efeito dos extrativos, portanto, é variável na qualidade energética da madeira, para queima direta ou para a conversão em carvão vegetal. O teor de extrativos pode aumentar ou diminuir o rendimento gravimétrico de carvão, dependendo da sua composição, especialmente da relação $\mathrm{O} / \mathrm{C}$ que influi estabilidade térmica do material (PEREIRA et al., 2013).

Na Figura 3 são apresentados os valores médios do teor de lignina total dos clones em função do local de plantio. 


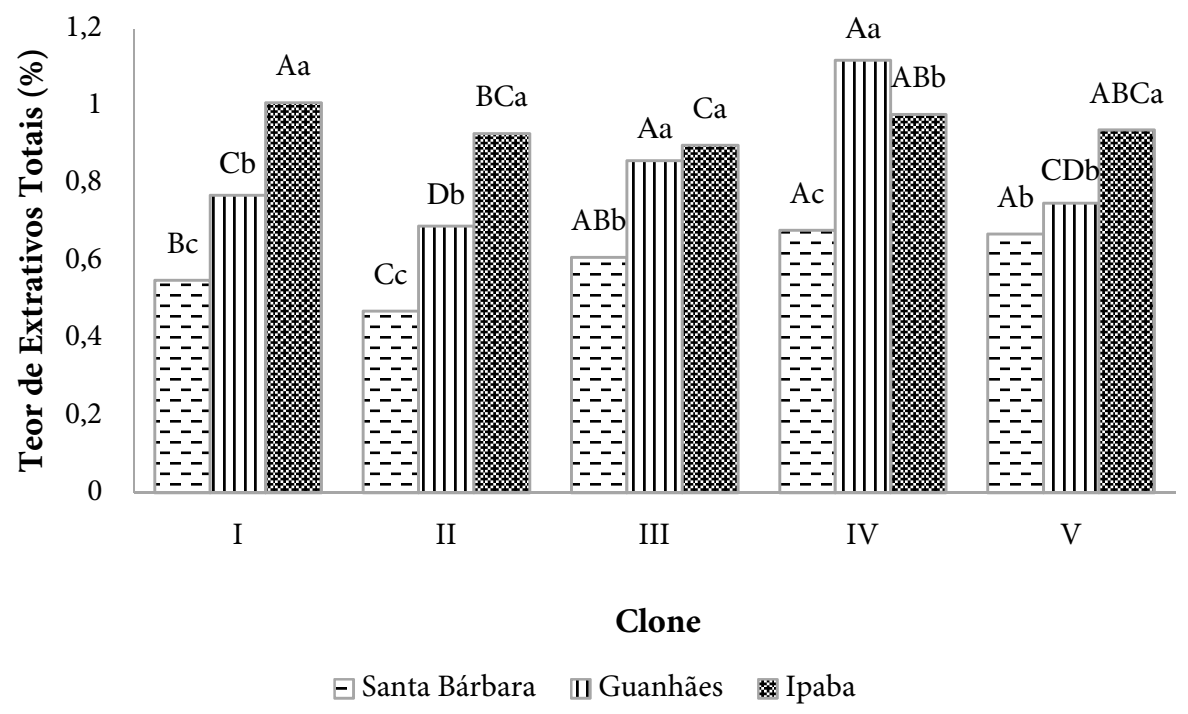

Médias seguidas de letras maiúsculas comparam clones e letras minúsculas comparam regiões de plantios pelo teste Tukey a $5 \%$ de significância.

Figura 2. Teor de extrativos da madeira de Eucalyptus sp. em função do material genético e do local de plantio.

Figure 2. Extractives content of Eucalyptus sp. wood as a function of genetic material and planting site.

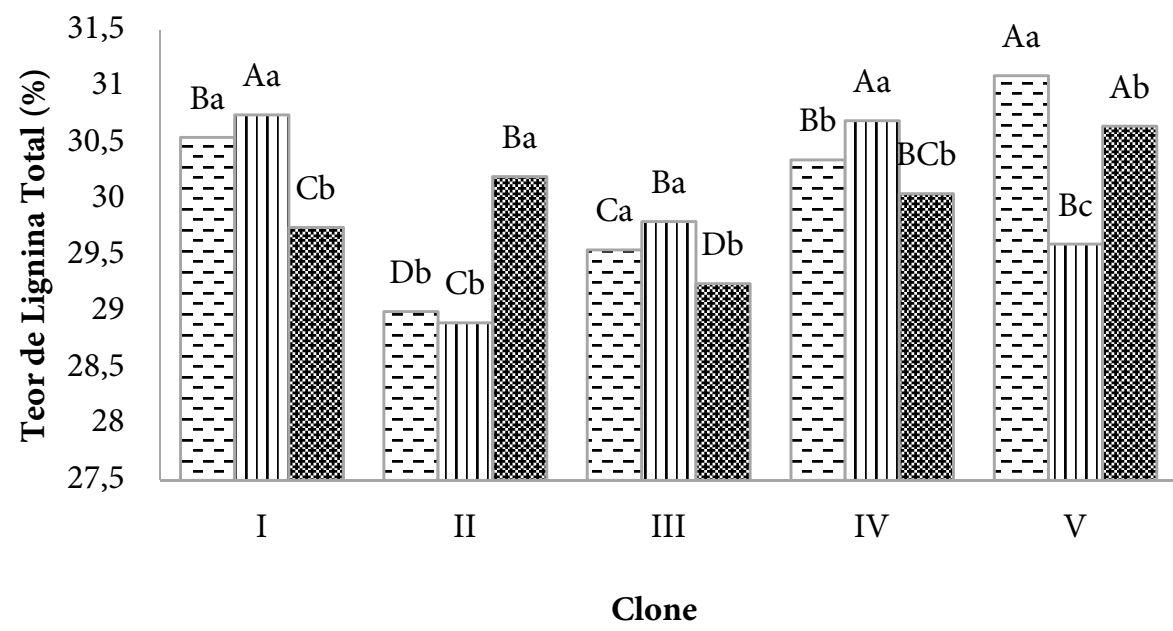

\section{Santa Bárbara \#IGuanhães Ipaba}

Médias seguidas de letras maiúsculas comparam clones e letras minúsculas comparam regiões de plantios pelo teste Tukey a $5 \%$ de significância.

Figura 3. Teor de lignina da madeira de Eucalyptus sp. em função do material genético e do local de plantio.

Figure 3. Lignin content of Eucalyptus sp. wood as a function of genetic material and planting site.

Nas regiões de Santa Bárbara e Ipaba os maiores teores de lignina foram observados para a madeira do clone $\mathrm{V}$, enquanto que na região de Guanhães, para a madeira dos clones I e IV. Os teores de lignina dos clones analisados variaram de $28,90 \%$ até $31,10 \%$. Esses valores são considerados altos para a madeira de folhosas, sendo teores de lignina acima de $30 \%$ mais comuns em madeiras de coníferas (GOMIDE e COLODETTE, 2007).

A lignina pode ser considerada o constituinte mais relevante para a produção de carvão vegetal. Materiais genéticos 
com alto teor de lignina apresentam maior rendimento gravimétrico em carvão, devido a estrutura complexa da lignina e sua maior resistência a degradação térmica (PEREIRA et al., 2013).

A composição química da madeira do gênero Eucalyptus sofre alterações de acordo com a idade das árvores (CARNEIRO et al., 2014). A composição química da madeira está sujeita a grandes variações dentro da zona juvenil e tende a valores mais estáveis, na madeira adulta. A madeira juvenil possui maiores teores de lignina do que a madeira adulta (TRUGILHO et al., 1996).

Na Figura 4 são apresentados os valores médios do teor de holoceluloses dos clones em função do local de plantio. Observa-se que, de modo geral, houve efeito significativo das duas variáveis nos valores desta propriedade.

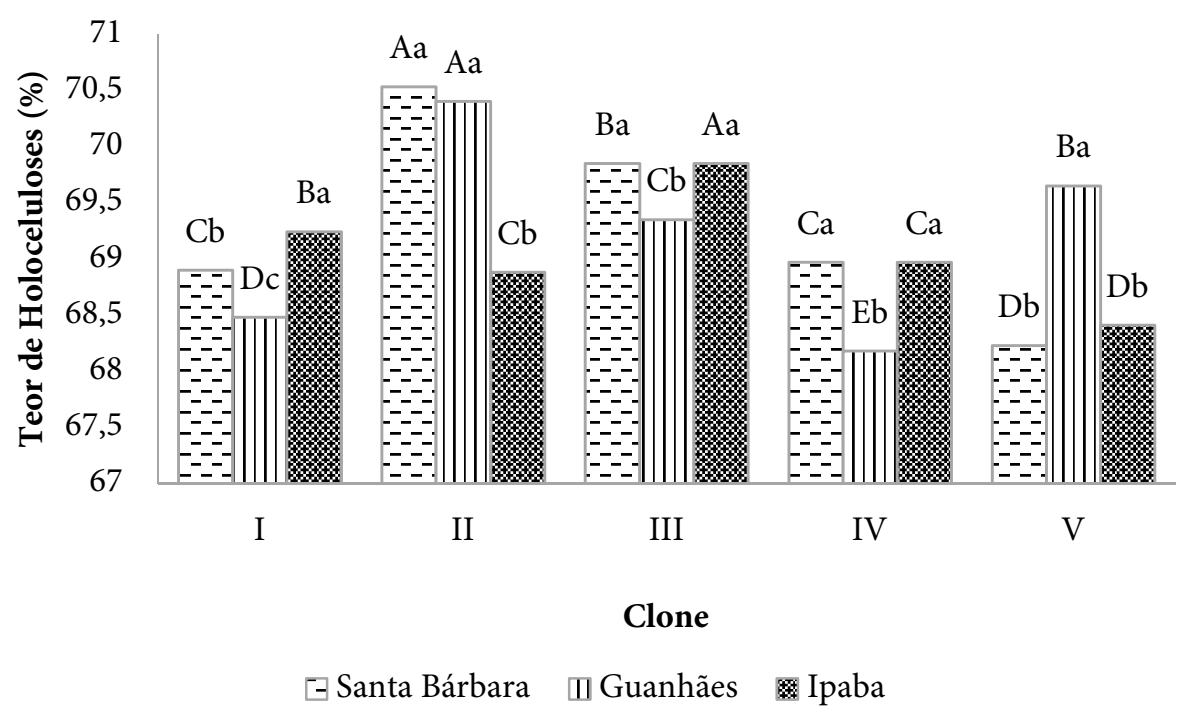

Médias seguidas de letras maiúsculas comparam clones e letras minúsculas comparam regiões de plantios pelo teste Tukey a $5 \%$ de significância.

Figura 4. Teor de holocelulose da madeira de Eucalyptus sp. em função do material genético e do local de plantio.

Figure 4. Holocellulose content of Eucalyptus sp. wood as a function of genetic material and planting site.

Na região de Santa Bárbara e Guanhães, os maiores teores de holoceluloses foram observados para a madeira do material genético II, enquanto que na região de Ipaba, o maior valor foi do material genético III.

A fração de holoceluloses na madeira corresponde a soma do teor de celulose e hemiceluloses presentes na madeira. A celulose e especialmente as hemiceluloses são os componentes menos resistentes a degradação térmica na madeira (HAYKIRI-ACMA et al., 2010). Quando se objetiva a produção de energia ou carvão vegetal são desejadas matérias primas com baixos teores de holoceluloses, pelo fato de este composto contribuir pouco para o rendimento gravimétrico (SHEN et al., 2010).

Observa-se que o menor teor de holoceluloses foi encontrado na região de Guanhães, que apresenta uma baixa fertilidade dos solos e uma baixa pluviosidade. A baixa disponibilidade hídrica no solo regula a síntese de foto assimilados, que por sua vez são os percursores para a produção de carboidratos (LARCHER, 1975).

Na Figura 5 são apresentados os valores médios do poder calorífico superior dos clones em função do local de plantio. 
$\mathrm{Na}$ região de Ipaba observa-se o maior poder calorífico para os materiais genéticos I, II e III, enquanto que, na região de Guanhães o material genético IV sobressaiu sobre os demais. Na região de Santa Bárbara o maior poder calorífico foi encontrado no clone V.

O poder calorífico da madeira está estreitamente ligado com a composição química estrutural da biomassa (PEREIRA et al., 2013). Para fins energéticos, o poder calorífico é um dos principais parâmetros utilizados para seleção de espécies, uma vez que está relacionada com a quantidade de energia liberada pela madeira durante a sua queima (CARNEIRO et al, 2014). A quantidade de calor desprendida é fundamental para o conhecimento da capacidade energética da biomassa.

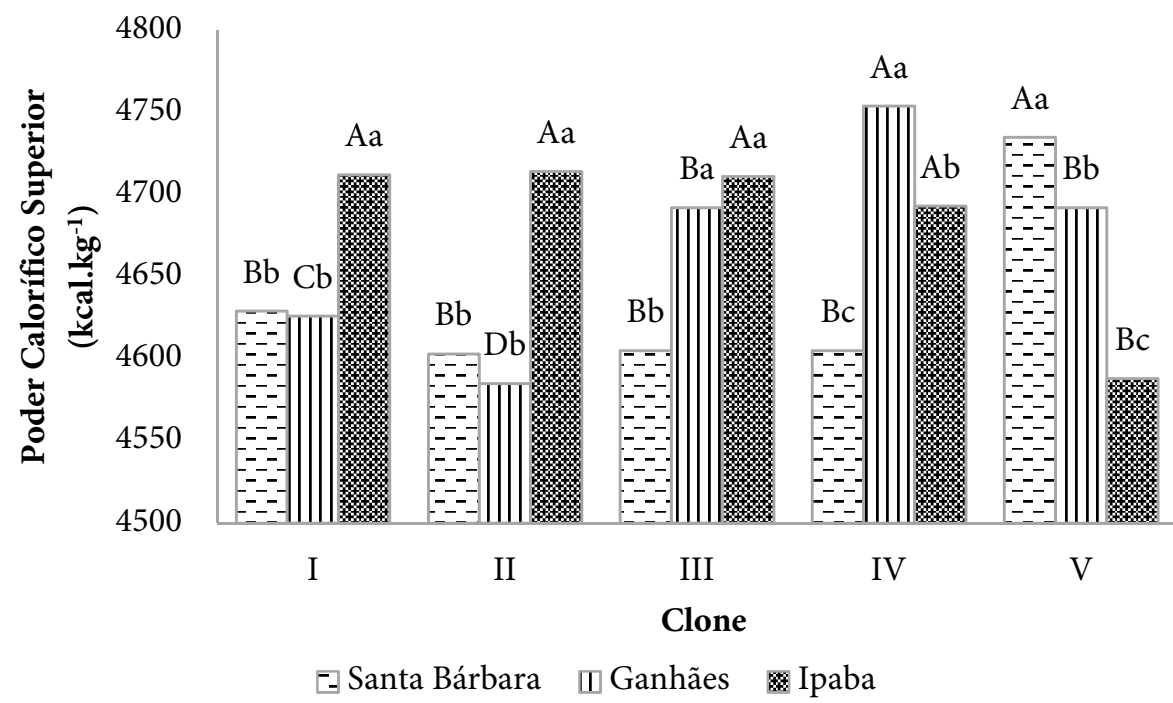

Médias seguidas de letras maiúsculas comparam clones e letras minúsculas comparam regiões de plantios pelo teste Tukey a $5 \%$ de significância.

Figura 5. Poder calorífico da madeira de Eucalyptus sp. em função do material genético e do local de plantio.

Figure 5. High heating value of Eucalyptus sp. wood as a function of the genetic material and planting site.

Tabela 2. Correlações entre as propriedades da madeira.

Table 2. Correlations between the wood properties.

\begin{tabular}{c|ccccc}
\multicolumn{1}{c}{} & DB & PCS & EXT & LIG & HOLO \\
\hline DB & 1 & 8,99 & 16,6 & $-33,8$ & 26,8 \\
PCS & - & 1 & $60,89^{*}$ & 26,28 & $-39,01$ \\
EXT & - & - & 1 & 24,1 & $-46,9^{*}$ \\
LIG & - & - & - & 1 & $-97,0^{*}$ \\
HOLO & - & - & - & -- & 1
\end{tabular}

Correlações significativas a 5\%* de probabilidade pelo teste T. Legenda: Densidade básica (DB); Poder calorífico superior (PCS); Teor de extrativos (EXT); Teor de lignina (LIG); Teor de holocelulose (HOLO).

O poder calorífico superior apresentou correlação positiva com os teores de extrativos possivelmente devido à presença de compostos com altos teores de carbono, como alguns extrativos de natureza fenólica, conforme a discussão da
Figura 2. O teor de holoceluloses apresentou alta correlação negativa com o teor de lignina, uma vez que ambos perfazem a quase totalidade da massa de madeira. Não houve correlação significativa entre o poder calorífico e o teor de lignina. 
Para a análise das propriedades da madeira, é necessário que cada parâmetro seja avaliado individualmente de acordo com sua finalidade. Assim, o material genético que é utilizado para produção de carvão vegetal, poderá não ser indicado para produção de energia.

\section{Conclusões}

Houve influência do material genético e do sítio na qualidade da madeira para fins energéticos.

Quando se objetiva a queima direta, para a produção de energia, os clones IV e V apresentaram o maior potencial de utilização, para todas as regiões estudadas. Em contrapartida, quando se objetiva a produção de carvão vegetal os clones $\mathrm{V}$ e II apresentaram o maior potencial de utilização, sendo o primeiro mais indicado para as regiões de Santa Bárbara e Guanhães e do segundo para a região de Ipaba.

\section{Agradecimentos}

Ao Conselho Nacional de Desenvolvimento Científico e Tecnológico (CPNq), a Coordenação de Aperfeiçoamento de Pessoal de Nível Superior (CAPES), a Fundação de Amparo à Pesquisa de Minas Gerais (FAPEMIG), Embrapa Florestas, Sociedade de Investigações Florestais (SIF) e ao G6 - Grupo Temático em Carvão Vegetal.

\section{Referências}

ASSOCIAÇÃO BRASILEIRA DE NORMAS TÉCNICAS ABNT. NBR 11941. Determinação da densidade básica da madeira. Rio de Janeiro, 2003. 6p.

BRITO, J. O. Reflexões sobre a qualidade do carvão vegetal para uso siderúrgico. Piracicaba: IPEF, 1993. (Circular Técnica, 181).

CARNEIRO, A. C. O. et al. Potencial energético da madeira de Eucalyptus sp. em função da idade e de diferentes materiais genéticos. Revista Árvore, v.38, n.2, p.375-381, 2014.
CASTRO, A.F.N.M. et al. Análise multivariada para seleção de clones de eucalipto destinados à produção de carvão vegetal. Pesquisa Agropecuária Brasileira, v.48, n.6, p.627-635, 2013.

CRUZADO, C.P.; MERINO, A.; SOALLEIRO, R.R. A management tool for estimating bioenergy production and carbon sequestration in Eucalyptus globulus and Eucalyptus nitens grown as short rotation woody crops in north-west Spain. Biomass and Bioenergy, v.35, p.2839-2851, 2011.

DEUTSCHES INSTITUT FÜR NORMUNG - DIN. EN 14918: Determination of calorific value. Belim: CEN, 2010. 63 p.

ELOY, E. et al. Influência do espaçamento nas características energéticas de espécies arbóreas em plantios de curta rotação. Revista Árvore, v.38, n.3, p.551-559, 2014.

EVANGELISTA W. V. et al. Propriedades físico-mecânicas da madeira de Eucalyptus urophylla S. T. Blake no sentido radial e longitudinal. Ciência da Madeira, v.1, n.02, p.1-19, 2010.

GARCÍA, M.G. et al. Above-ground biomass estimation at tree and stand level for short rotation plantations of Eucalyptus nitens (Deane \& Maiden) Maiden in Northwest Spain. Biomass and Bioenergy, v.54, p.147-157, 2013.

GARSTANG, J. et al. Identification and characterisation of factors affecting losses in the large-scale, non-ventilated bulk storage of wood chips and development of best storage practices. Report. FES B/W2/00716/RESP.DTI/Pub urn 02/1535: 2002. 116p.

GOMIDE, J. L.; COLODETTE, J. L. Qualidade da madeira. In: BOREM, A. (Ed.) Biotecnologia Florestal. Viçosa, MG: Universidade Federal de Viçosa, 2007. p.25-54.

HAYKIRI-ACMA, H.; YAMAN, S.; KUCUKBAYRAK, S. Comparison of the thermal reactivities of isolated lignin and holocellulose during pyrolysis. Fuel Processing Technology, v.91, p. 759-764, 2010.

LARCHER, W. Physiological plant ecology. New York: Springer - Verlag, 1975. 252p.

OLIVEIRA, A.C. et al. Avaliação de diferentes níveis de desbaste nas propriedades da madeira e do carvão vegetal de $E u$ calyptus grandis x Eucalyptus urophylla. Floresta, v. 42, n.1, p.59-68, 2012. 
OLIVEIRA, A.C. et al. Parâmetros de qualidade da madeira e do carvão vegetal de Eucalyptus pellita F. Muell. Scientia Forestalis (IPEF), v.38, p.431-439, 2010.

OLIVEIRA, J.G.L. et al. Parâmetros quantitativos da anatomia da madeira de eucalipto que cresceu em diferentes locais. Revista Árvore, v.36, n.3, p.559-567, 2012.

PEREIRA, B.L.C. et al. Quality of Wood and Charcoal from Eucalyptus Clones for Ironmaster Use. International Journal of Forestry Research, v.2012, p.1-8, 2012.

PEREIRA, B.L.C. et al. Influence of Chemical Composition of Eucalyptus Wood on Gravimetric Yield and Charcoal Properties. BioResources, v.8, n.3, p.4574-4592, 2013.

ROWELL, R. M. et al. Cell wall chemistry. In: ROWELL, R. (Ed.). Handbook of wood chemistry and wood composites. Boca Raton: CRC, 2005. p.35-74.

SANTOS, F.; COLlODETTE, J.; QUEIROZ, J. H. (Ed.). Viçosa: Os editors, 2013. p. 321-354.

SHEN, R.; GU, S.; BRIDGWATER, A.V. The thermal performance of the polysaccharides extracted from hardwood: Cellulose and hemicelluloses. Carbohydrate Polymers, V.82, p. 39-45, 2010.

TRUGILHO, P.F. et al. Características de crescimento, composição química, física e estimativa de massa seca de madeira em clones e espécies de Eucalyptus jovens. Ciência Rural (UFSM. Impresso), v. 45, p. 661-666, 2015.

TRUGILHO, P.F.; LIMA, J.T.; MENDES, L.M. Influência da idade nas características físico-químicas e anatômicas da madeira de Eucalyptus saligna. Cerne, v.2, n.1, 15p, 1996.

VALE, A. T.; BRASIL, M. A. M.; LEÃO, A. L. Quantificação e caracterização energética da madeira e casca de espécies do cerrado. Ciência Florestal, v.12, n.1, p.71-80, 2002.

VIDAURRE, G. et al. Lenho Juvenil e Adulto e as Propriedades da Madeira. Floresta e Ambiente, v.18(4), p.469-480, 2011.

VITAL, B. R.; CARNEIRO, A. C. O.; PEREIRA, B. L. C. Qualidade da madeira para fins energéticos. In: Bioenergia \& Biorrefinaria - Cana-de-Açúcar \& Espécies Florestais. 